\title{
The socioeconomic burden of chronic lung disease in low-resource settings across the globe - an observational FRESH AIR study
}

Evelyn A. Brakema ${ }^{1 *}$ D, Aizhamal Tabyshova ${ }^{2,3}$, Rianne M. J. J. van der Kleij ${ }^{1}$, Talant Sooronbaev ${ }^{2}$, Christos Lionis ${ }^{4}$, Marilena Anastasaki ${ }^{4}$, Pham Le An ${ }^{5}$, Luan Than Nguyen ${ }^{5}$, Bruce Kirenga ${ }^{6}$, Simon Walusimbi ${ }^{6}$, Maarten J. Postma ${ }^{3}$, Niels H. Chavannes', Job F. M. van Boven ${ }^{7}$ and On behalf of the FRESH AIR collaborators

\begin{abstract}
Background: Low-resource settings are disproportionally burdened by chronic lung disease due to early childhood disadvantages and indoor/outdoor air pollution. However, data on the socioeconomic impact of respiratory diseases in these settings are largely lacking. Therefore, we aimed to estimate the chronic lung disease-related socioeconomic burden in diverse low-resource settings across the globe. To inform governmental and health policy, we focused on work productivity and activity impairment and its modifiable clinical and environmental risk factors.

Methods: We performed a cross-sectional, observational FRESH AIR study in Uganda, Vietnam, Kyrgyzstan, and Greece. We assessed the chronic lung disease-related socioeconomic burden using validated questionnaires among spirometry-diagnosed COPD and/or asthma patients (total $N=1040$ ). Predictors for a higher burden were studied using multivariable linear regression models including demographics (e.g. age, gender), health parameters (breathlessness, comorbidities), and risk factors for chronic lung disease (smoking, solid fuel use). We applied identical models per country, which we subsequently meta-analyzed.

Results: Employed patients reported a median [IQR] overall work impairment due to chronic lung disease of $30 \%$ [1.8-51.7] and decreased productivity (presenteeism) of 20.0\% [0.0-40.0]. Remarkably, work time missed (absenteeism) was $0.0 \%$ [0.0-16.7]. The total population reported 40.0\% [20.0-60.0] impairment in daily activities. Breathlessness severity (MRC-scale) $(B=8.92,95 \% C l=7.47-10.36)$, smoking $(B=5.97,95 \% C l=1.73-10.22)$, and solid fuel use $(B=3.94,95 \% C l=0.56-7.31)$ were potentially modifiable risk factors for impairment.

Conclusions: In low-resource settings, chronic lung disease-related absenteeism is relatively low compared to the substantial presenteeism and activity impairment. Possibly, given the lack of social security systems, relatively few people take days off work at the expense of decreased productivity. Breathlessness (MRC-score), smoking, and solid fuel use are potentially modifiable predictors for higher impairment. Results warrant increased awareness, preventive actions and clinical management of lung diseases in low-resource settings from health policymakers and healthcare workers.
\end{abstract}

Keywords: Chronic respiratory disease, Chronic lung disease, Obstructive lung disease, WPAl, Health economics, Lowincome population, Work, Low-resource countries, Household air pollution

\footnotetext{
*Correspondence: evelynbrakema@gmail.com

'Department of Public Health and Primary Care, Leiden University Medical

Center, Postzone V0-P, Postbus 9600, 2300 RC Leiden, The Netherlands

Full list of author information is available at the end of the article
}

(c) The Author(s). 2019 Open Access This article is distributed under the terms of the Creative Commons Attribution 4.0 International License (http://creativecommons.org/licenses/by/4.0/), which permits unrestricted use, distribution, and reproduction in any medium, provided you give appropriate credit to the original author(s) and the source, provide a link to the Creative Commons license, and indicate if changes were made. The Creative Commons Public Domain Dedication waiver (http://creativecommons.org/publicdomain/zero/1.0/) applies to the data made available in this article, unless otherwise stated. 


\section{Background}

Low- and middle-income countries account for more than $90 \%$ of the global COPD mortality and $80 \%$ of the asthma mortality [1]. Also regarding the socioeconomic burden, low-resource settings seem disproportionally affected [2-4]. In these settings, increased predisposition to chronic lung diseases (CLDs) already starts in-utero due to high exposure to environmental risk factors (such as excessive indoor and outdoor air pollution) and poorer living conditions (e.g. undernutrition) [3, 5-12]. Hence CLDs develop in a younger, primarily workingage, population [5, 13-15]. Furthermore, the patient burden is particularly high in low-resource settings, because CLDs manifest themselves more severely due to suboptimal (access to) care, including diagnostic- and treatment options $[2-4,16]$. Severe CLDs can impact patients' daily activities substantially [17]. With often limited or non-existent social security systems, families are left in severe trouble when their breadwinner can no longer support them financially [2, 18]. Paradoxically, most studies on the CLD-associated socioeconomic burden have been performed in high-resource settings. The urgency of evaluating outcomes specifically in lowresource settings was therefore underlined recently [19]. In particular, the need for social, economic, and policy research was highlighted as crucial for diminishing the burden of CLD in LMICs [12].

An important form of the social burden of CLD is impairment of patients' daily activities [17]. On top of that comes the direct economic burden (such as medication and hospital visits) and indirect economic burden (such as productivity loss at work) $[20,21]$. While widely available in high income countries, data on the social and indirect economic burden in low-resource settings remain especially scarce $[2,22,23]$. One study reported on an indirect burden, unemployment, for both high- and lowresource settings [24]. It observed a relation between chronic airflow obstruction and unemployment only for high-resource settings. However, as employment was a dichotomized outcome, disease-related hours missed from work (absenteeism) were not taken into account. In addition, while being at work, symptoms of CLD can seriously impact productivity (presenteeism). Presenteeism is more responsive to asthma control than absenteeism and is a vital source of preventable burden [20]. Hence, the actual socioeconomic impact of CLDs in low-resource settings has yet to be uncovered.

Gaining more knowledge on the actual socioeconomic burden is of critical importance to adequately inform policymakers, healthcare professionals, and community members on the impact of CLDs [12]. Evidence on the burden can raise awareness and encourage prioritization of the use of scarcely available resources for CLDs, so that these can be approached with highly (cost-)effective interventions [2, 3]. Furthermore, there is a need to identify (modifiable) risk factors for impairment [25], which may allow targeted interventions. Therefore, the aim of this study was to estimate the socioeconomic burden of CLD in diverse low-resource settings across the globe. To inform governmental and public health policy, we focused on work productivity and activity impairment and its modifiable clinical and environmental risk factors.

\section{Methods}

This study was part of the FRESH AIR project (Free Respiratory Evaluation and Smoke-exposure reduction by primary Health cAre Integrated gRoups; trial registration number: NTR5759), targeting (implementation of) the prevention, diagnosis, and treatment of CLDs in lowresource settings [26]. An online supplement provides additional information on the methods (Additional file 1: Appendix 2).

\section{Design and setting}

This observational, cross-sectional study was performed between July 2016 and March 2018 in Uganda, Vietnam, Kyrgyzstan, and rural Greece. The study sites were sampled purposefully to represent four distinct low-resource settings in terms of geography, ethnicity, risk factor exposure, and healthcare- and political system. At these sites, we selected healthcare centers routinely using spirometry to diagnose CLDs (asthma, COPD, or asthma-COPD overlap (ACO)). The exact selection method of settings and participants was designed in close collaboration with the local teams to meet their daily clinical routine, typical patient population, and available resources (Additional file 1: Appendix 2; Table E1).

\section{Participants}

We recruited participants consecutively during visits to the selected health centers (Additional file 1: Appendix 2 Table E1). We included patients $\geq 15$ years with a spirometry-confirmed diagnosis of COPD [27], asthma or ACO [28]. We did not deploy additional inclusion criteria for COPD (age, tobacco use), as patients in lowresource settings may develop COPD earlier in life due to disadvantage factors such as household air pollution $[5,6,10,13]$. Patients with a disability hampering communication, too severely ill to participate, or with missing outcomes on activity impairment, were excluded.

\section{Procedures}

Eligible participants were identified and informed about the study by their physicians during a routine visit. After consent, participants filled out a questionnaire. Their physician added the clinical data from existing medical history files. In three hospitals in Kyrgyzstan, well- 
organized patient registries allowed research-assistants to recruit participants per telephone to administer the questionnaire (Additional file 1: Appendix 2 provides further details on the procedures).

\section{Instruments}

The questionnaire was composed of several validated $[29,30]$, structured questionnaires with additional openended questions, assessing demographic, socioeconomic, and health factors (Additional file 1: Appendix 3). The outcome work- and other activity impairment was assessed using the recommended Work Productivityand Activity Impairment (WPAI) questionnaire [30-32]. The WPAI-questionnaire assesses CLD -related absenteeism, presenteeism, overall work impairment (absenteeism and presenteeism combined), and impairment of regular activities during the preceding 7 days [30]. All items are calculated into percentages (Additional file 1: Appendix 3), with higher numbers indicating greater impairment and less productivity. When available, we used official, validated WPAI-translations [33].

All questions were asked in the local language (English, Vietnamese, Russian, Greek). In Uganda, where several local languages are spoken, the involved research-team represented all major language groups. We piloted the questionnaire and improved the translation and contextual adaptations accordingly. For example, as many patients were unaware of the name of their disease, we added clarifications on CLDs before asking about the impact of their 'COPD' and/or 'asthma'.

\section{Sample size}

With a total covered population of $+/-146$ million (Uganda: 40; Kyrgyzstan: 6; Vietnam: 90; Greece: 10 million), an estimated global CLD-prevalence of 5\% [22, 34], a number of 1040 participants resulted in a $99 \%$ confidence level and a 4\% error margin. Notably, CLDprevalence is mostly unknown in our diverse lowresource settings. Therefore, the sample size was not calculated to compare between countries and not weighted based on country-size or differences in prevalence.

\section{Statistical analysis}

Population characteristics and the WPAI were analyzed using descriptive statistics (SPSS version 25; IBM, Armonk, NY, USA). The relation between predictors and activity impairment was first assessed per country, using univariable and forced-entry multivariable linear regressions. An identical regression model was used for each country, based on known risk factors for impairment (Additional file 1: Appendix 2) [35-37]. We added solid fuel use for cooking/heating, as besides smoking this is another major risk factor for CLD in low-resource settings $[1,8,10,38]$. There were no indications for multicollinearity. The unstandardized coefficients of each country with their 95\% confidence intervals (CI) were then meta-analyzed (Comprehensive Meta-Analysis version 3; Biostat, Englewood, NJ, USA). We generally used a fixed-model. Only for 'comorbidity' we used a random-effect model, as for this variable there were indications for heterogeneity of effect between the countries. Because our Kyrgyz population had no asthma patients, we performed a separate meta-analysis without this country to check for any differences (Additional file 1: Appendix 4 Table E4). Coefficients with $95 \% \mathrm{CI}$ excluding 1 were considered statistically significant.

\section{Results}

\section{Clinical and demographic characteristics}

We included a total of 1040 participants (Fig. 1); most were recruited in Vietnam and Kyrgyzstan. Almost half of the total population was male, and the median age was 60.0 [IQR 48.0-70.0] (Table 1). The Ugandan population consisted of more female and younger participants, whereas the other countries' populations consisted of somewhat more male participants of older age. A slight majority of the participants was diagnosed with COPD (55.1\%), followed by asthma (38.5\%), and a small number with ACO (6.4\%). Breathlessness severity was generally moderate (median MRC-score 3.0; IQR 2.0-4.0). Having at least one comorbidity was common (34.7\%), with heart disease being most prevalent (Additional file 1: Appendix 4 Table E1). Risk factors for developing CLD were highly prevalent, such as having ever smoked daily (43.9\% of whom $91.7 \%$ male), solid fuel use (54.0\%) and occupational exposure to dust or fumes (59.4\% of the 401 workers). The distribution of risk factors differed across the countries. For example, in Uganda, smoking prevalence was extremely low (3.5\%) compared to solid fuel use $(98.8 \%)$, whereas in Greece this was the other way around (68.9 and $49.4 \%$ respectively). Clinical and demographic details are reported in Additional file 1: Appendix 4 Table E1.

\section{Work productivity and activity impairment}

Locally, 533 participants (51.2\%) were considered to be of working age (Additional file 1: Appendix 4 Table E1). Although 401 identified themselves as 'working', 270 $(67.3 \%)$ of those worked for a salary at an employer. WPAI-scores were generally very similar across the countries. However, in Kyrgyzstan, all scores were higher (Fig. 2, Table 2). Still, a similar pattern was visible in each country: while CLD-related absenteeism was (relatively) very low among those employed, presenteeism was relatively high, leading to a substantial overall work impairment. Activity impairment was considerably high, particularly in the total population. To facilitate interpretation of the outcomes within their country, WPAI- 


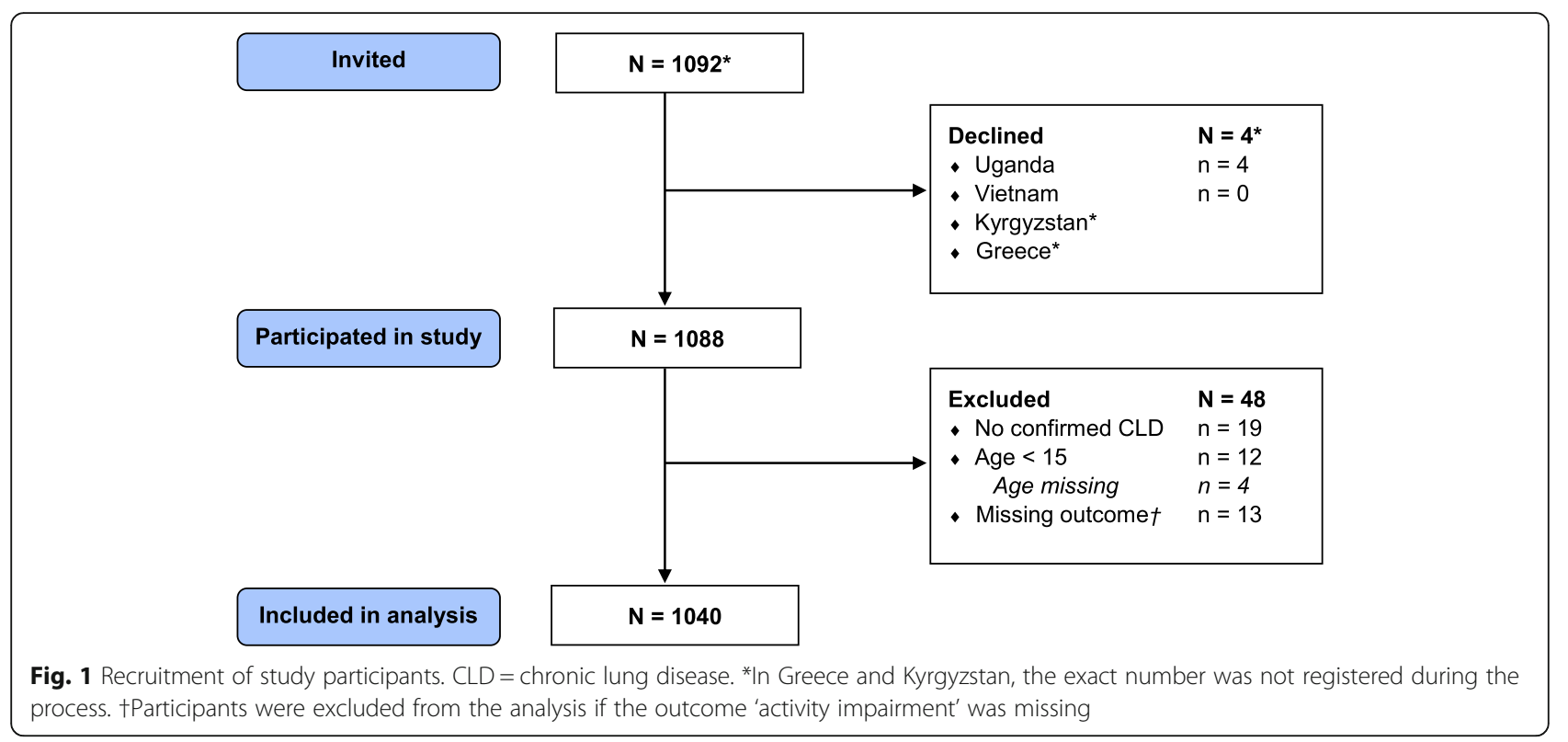

scores and their 95\% CIs are provided in Additional file 1: Appendix 4 Table E2.

The proportion of patients that suffered from any degree of impairment due to their CLD during the past seven days was also high for all four WPAI outcomes. Although many patients missed any amount of work time (43.0\%), the work time they missed was very low. On the contrary, the proportion of patients who suffered from activity impairment was much higher $(86.4 \%)$ and also the level of activity impairment was high.

\section{Risk factors for activity impairment}

For data-orientation, univariable regressions are presented in Additional file 1: Appendix 4 Table E3. In each of the individual country multivariable analyses and in the meta-analysis, breathlessness severity (MRC-score) was identified as a robust predictor for activity impairment (Fig. 3, 4, 5, Additional file 1: Appendix 4 Table E4). Other significant predictors in the meta-analyses were working (inversely related), smoking, and solid fuel use. The results were similar for both meta-analyses (i.e. regardless of excluding Kyrgyzstan from the analysis). Besides activity impairment, MRC-score was identified as a predictor for both presenteeism and overall work impairment. In contrast, absenteeism remained relatively low, independent of MRC-score (Fig. 5b).

\section{Discussion}

We have evaluated the socioeconomic burden of CLD in low-resource settings across the globe, with a specific focus on work- and activity impairment and its risk factors. Our findings demonstrate substantial disease-related productivity impairment, overall work impairment, and activity impairment. Remarkably, absenteeism consistently remained relatively low. Severity of breathlessness, smoking, and solid fuel use were modifiable predictors for impairment.

The patterns of absenteeism and presenteeism we have identified are similar in high-resource settings [23]. However, in our study, absolute WPAI-scores were considerably higher for all outcomes but absenteeism. Possibly, absenteeism remains low in low-resource settings, because limited or non-existent social security systems [2, 18] 'force' employees to show up at work, at the expense of a decreased productivity. Note that all WPAI-data should be interpreted within their context. The different sample sizes and diverse population characteristics would not allow for direct comparison of WPAI-scores between countries. Although participants were included using similar methods, countries and settings were selected based on diversity. The diversity-based selection resulted, for example, in differences in proportions of COPD-patients and breathlessness severity. To illustrate, Kyrgyz WPAIscores were high compared to scores in the other countries; breathlessness severity (a strong predictor) was high in Kyrgyzstan too. Breathlessness severity could be high because of lower ambient oxygen levels in the mountains. Absenteeism could particularly be impacted by the extreme temperatures $\left(-20^{\circ} \mathrm{C}\right.$ in winter) and rough Kyrgyz terrains in the Kyrgyz setting, forming barriers to travelling to/from work. Hence, only considered within this context, Kyrgyz WPAI-outcomes provide meaningful information, based on real-world data on CLD-related impairment [39].

Severity of breathlessness was already reported as a predictor for impairment for higher-resource settings [36, 40, 41]; we are the first to confirm this for lowresource settings. Besides activity impairment, also presenteeism and overall work impairment increased linearly 
Table 1 Clinical and demographic characteristics

\begin{tabular}{|c|c|c|c|c|c|}
\hline & $\begin{array}{l}\text { Uganda } \\
N=173(16.6 \%)\end{array}$ & $\begin{array}{l}\text { Vietnam } \\
N=471(45.3 \%)\end{array}$ & $\begin{array}{l}\text { Kyrgyzstan } \\
N=306(29.4 \%)\end{array}$ & $\begin{array}{l}\text { Greece } \\
N=90(8.7 \%)\end{array}$ & $\begin{array}{l}\text { Total } \\
N=1040(100 \%)\end{array}$ \\
\hline \multicolumn{6}{|l|}{ Demographic characteristics } \\
\hline Male & $39(22.5)$ & $274(58.2)$ & $188(61.4)$ & $55(61.1)$ & $556(53.3)$ \\
\hline Age (yrs.), median [IQR] & $35.0[22.5-47.0]$ & $62.0[52.0-72.0]$ & $62.0[55.0-70.0]$ & $72.0[63.8-79.0]$ & $60.0[48.0-70.0]$ \\
\hline $\mathrm{BMI}\left(\mathrm{kg} / \mathrm{m}^{2}\right)$, median [IQR] & $23.8[20.4-28.3]$ & $21.9[19.5-24.4]$ & $25.8[23.7-29.4]$ & $28.0[24.7-31.5]$ & $23.9[20.8-27.3]$ \\
\hline Higher education $^{a}$ & $46(26.7)$ & $156(33.1)$ & $291(95.1)$ & $4(4.4)$ & $497(47.8)$ \\
\hline \multicolumn{6}{|l|}{ Working status } \\
\hline Working & $93(53.8)$ & $193(41.1)$ & $92(30.1)$ & $23(25.6)$ & $401(38.6)$ \\
\hline Employed (for payment) & $81(87.1)$ & $134(69.4)$ & $40(43.5)$ & $15(65.2)$ & $270(67.3)$ \\
\hline Not working & $41(23.7)$ & $153(32.6)$ & $34(11.1)$ & $13(14.4)$ & $241(23.2)$ \\
\hline Student & $36(20.0)$ & $5(1.1)$ & $0(0.0)$ & $0(0.0)$ & $41(3.9)$ \\
\hline Retired & $3(1.7)$ & $119(25.3)$ & $180(58.8)$ & $54(60.0)$ & $356(34.2)$ \\
\hline Having child (ren) & $117(67.6)$ & $417(88.5)$ & $302(98.7)$ & 79 (87.8) & $915(88.0)$ \\
\hline Ever smoker & $6(3.5)$ & $251(53.3)$ & $138(45.1)$ & $62(68.9)$ & $457(43.9)$ \\
\hline Pack years, median [IQR] & $3.8[2.0-19.9]$ & $29.0[15.5-44.0]$ & $27.0[14.2-40.8]$ & $57.0[26.1-74.0]$ & $30.0[15.1-45.0]$ \\
\hline Male & $4(66.7)$ & $234(93.2)$ & $134(97.1)$ & $47(75.8)$ & $419(91.7)$ \\
\hline Current smoker & $6(100.0)$ & $92(36.7)$ & $37(26.8)$ & $40(64.5)$ & $175(38.3)$ \\
\hline Solid fuel use & $170(98.8)$ & $130(27.6)$ & $218(71.5)$ & $44(49.4)$ & $562(54.0)$ \\
\hline Occupational exposure ${ }^{b}$ & $87(93.5)$ & $104(53.9)$ & $37(40.2)$ & $10(43.5)$ & $238(59.4)$ \\
\hline \multicolumn{6}{|l|}{ Health characteristics } \\
\hline \multicolumn{6}{|l|}{ Diagnosed as: } \\
\hline COPD & $11(6.4)$ & $190(40.3)$ & $305(99.7)$ & $67(74.4)$ & $573(55.1)$ \\
\hline Asthma & $161(93.1)$ & $223(47.3)$ & $0(0.0)$ & $16(17.8)$ & $400(38.5)$ \\
\hline ACO & $1(0.6)$ & $58(12.3)$ & $1(0.3)$ & $7(7.8)$ & $67(6.4)$ \\
\hline Breathlessness severity (MRC-scale), median [IQR] & $2.0[1.0-2.0]$ & $3.0[2.0-4.0]$ & $4.0[3.0-4.0]$ & $2.0[2.0-4.0]$ & $3.0[2.0-4.0]$ \\
\hline Exacerbation(s) in past year & $0(0.0)$ & $102(21.7)$ & $35(11.4)$ & $9(10.0)$ & $146(14.0)$ \\
\hline Comorbidity (any) & $27(15.6)$ & $228(48.4)$ & $62(20.3)$ & $44(48.9)$ & $361(34.7)$ \\
\hline
\end{tabular}

Data are in numbers (\%) unless stated otherwise. ACO asthma-COPD overlap, BMI body mass index, IQR interquartile range, MRC medical research council. Text in italics means category within category above. ${ }^{a}$ Above secondary education. ${ }^{b}$ Regards only those working. Missing values $\mathrm{N}(\%)$ for BMI $6(0.6)$ in $\mathrm{G}$; education 1 $(0.1)$ in $\mathrm{U}$; working status $1(0.1)$ in $\mathrm{V}$; pack years $13(1.2) 1$ in $\mathrm{G}, 2$ in $\mathrm{V}, 10$ in $\mathrm{K}$; solid fuel use $3(0.3) 1$ in $\mathrm{U}, \mathrm{K}$, and G; MRC-score $1(0.1)$ in $\mathrm{U}$; exacerbation $1(0.1)$ in $\mathrm{G}$

with MRC-scores. Meanwhile, absenteeism consistently remained remarkably low despite severe breathlessness. This seems plausible, as most people with severe breathlessness have stopped working (severe breathlessness was significantly more common in our non-working population). Yet, if employed, again they ensure not to miss worktime as social security is limited.

We argue severe breathlessness may be inherent to low-resource settings, because access to healthcare and adequate equipment is limited in low-resource settings [2, 3, 16]. Therefore, a) possibly only the more severely ill patients receive a spirometryconfirmed CLD-diagnosis (one of our inclusion criteria) and b) undertreatment is common and could trigger severe symptoms. Second, low-resource settings have higher and earlier exposure to behavioral and environmental risk factors $[3,5-7,10,14,42]$
(45\% of our Kyrgyz population smoked, and the entire rural population relies on solid fuels for cooking and heating) [8]. This can result in more severe disease and hence, more breathlessness. Interestingly, higher and earlier exposure to risk factors in lower-resource settings also lead to earlier onset of disease. In combination with lower life-expectancies in lowerresource countries, this explains why the age of the patient population in Uganda was generally lower than in Vietnam and Kyrgyzstan, where in turn it was lower than in Greece.

In addition to breathlessness, both tobacco- and solid fuel use were identified as modifiable risk factors for impairment. Tobacco use was already known to predict CLD-related impairment in high-resource settings, whereas solid fuel use is newly identified and typical for low-resource settings. Furthermore, 'working' was a 


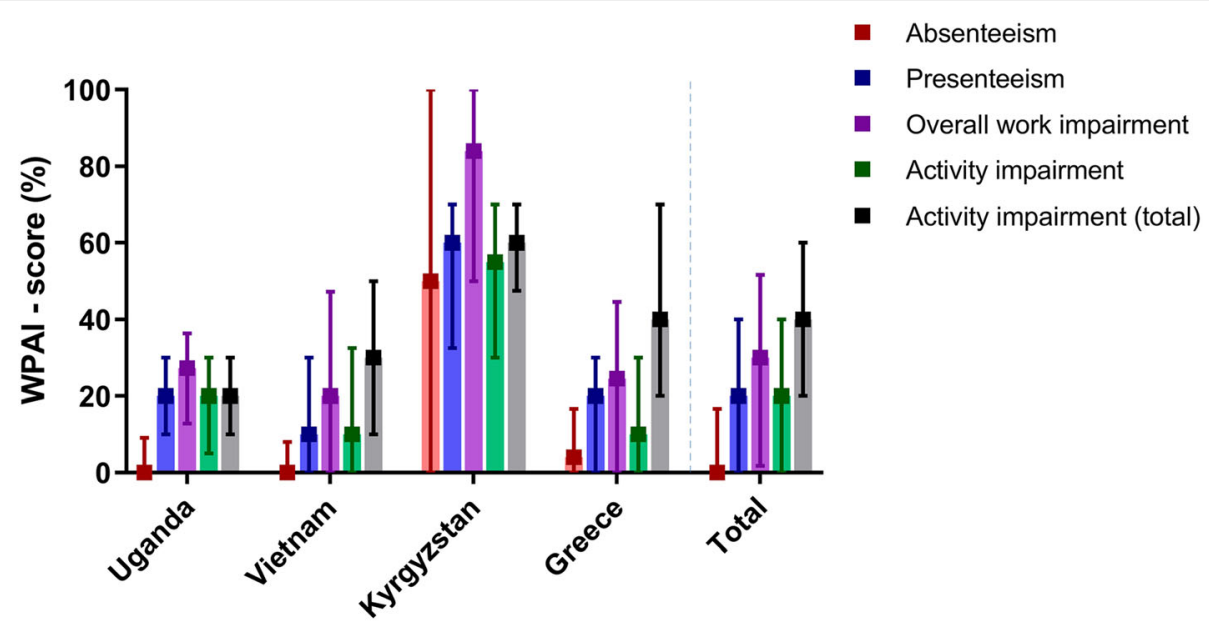

Fig. 2 Work productivity and activity impairment due to CLD. CLD = chronic lung disease; WPAI = work productivity and activity impairment in median [interquartile range] \%. 100\% means maximum impairment. Total number of participants (numbers of employed population): Uganda $N=173$ (81), Vietnam 471 (134), Kyrgyzstan 306 (40), Greece 90 (15), and total 1040 (270). Due to different population characteristics per country, data should be interpreted within the country's context and not be used to directly compare between countries

protective factor for activity impairment. Similarly, higher activity impairment for part-time compared to fulltime employees was reported in a high-resource setting [35]. Of note, age was a significant predictor in univariable regression analyses but turned insignificant in the multivariable analyses. We assume the effect of 'age' diminished in the multivariable model because of the presence of the more accurate predictor 'breathlessness severity' (and commonly, like age, breathlessness severity increases over time).

Table 2 CLD-related work productivity and activity impairment (WPAI)

\begin{tabular}{|c|c|c|c|c|c|}
\hline WPAl item & Uganda & Vietnam & Kyrgyzstan & Greece & Total \\
\hline \multicolumn{6}{|l|}{ Employed population } \\
\hline \multicolumn{6}{|l|}{ Absenteeism } \\
\hline$\%$ work time missed due to CLD & $0.0[0.0-9.1]$ & $0.0[0.0-8.0]$ & $50.0[0.0-100.0]$ & $4.0[0.0-16.7]$ & $0.0[0.0-16.7]$ \\
\hline $\begin{array}{l}\% \text { of the people who missed any work due } \\
\text { to CLD, mean }(95 \% \mathrm{Cl})\end{array}$ & $46.8(35.6-58.1)$ & $31.5(23.3-39.7)$ & $70.0(55.2-84.8)$ & $50.0(20.0-80.0)$ & $43.0(36.9-49.1)$ \\
\hline \multicolumn{6}{|l|}{ Presenteeism } \\
\hline$\%$ impairment while working due to CLD & $20.0[10.0-30.0]$ & $10.0[0.0-30.0]$ & $60.0[32.5-70.0]$ & $20.0[0.0-30.0]$ & $20.0[0.0-40.0]$ \\
\hline $\begin{array}{l}\% \text { of the people whose productivity was } \\
\text { affected, mean }(95 \% \mathrm{Cl})\end{array}$ & $77.2(67.8-86.7)$ & $62.2(53.7-70.8)$ & $100.0(100.0-100.0)$ & $71.4(44.4-98.5)$ & $72.9(67.4-78.3)$ \\
\hline \multicolumn{6}{|l|}{ Overall work impairment } \\
\hline Absenteeism and presenteeism combined & $27.3[12.9-36.7]$ & $20.0[0.0-47.3]$ & $84.0[50.0-100.0]$ & $24.5[0.0-44.6]$ & $30.0[1.8-51.7]$ \\
\hline $\begin{array}{l}\% \text { of people who suffered from any work } \\
\text { impairment, mean }(95 \% \mathrm{Cl})\end{array}$ & $79.7(70.7-88.8)$ & $65.4(57.0-73.7)$ & $100.0(100.0-100.0)$ & $71.4(44.4-98.5)$ & $75.2(69.9-80.5)$ \\
\hline \multicolumn{6}{|l|}{ Activity impairment } \\
\hline$\%$ impairment of activities due to CLD & $20.0[5.0-30.0]$ & $10.0[0.0-32.5]$ & $55.0[30.0-70.0]$ & $10.0[0.0-30.0]$ & $20.0[0.0-40.0]$ \\
\hline $\begin{array}{l}\% \text { of the people whose daily activities were } \\
\text { affected, mean }(95 \% \mathrm{Cl})\end{array}$ & $75.9(66.3-85.6)$ & $61.4(52.8-70.0)$ & $100.0(100.0-100.0)$ & $53.8(22.5-85.2)$ & $71.5(66.1-76.9)$ \\
\hline \multicolumn{6}{|l|}{ Total population } \\
\hline \multicolumn{6}{|l|}{ Activity impairment } \\
\hline$\%$ impairment of activities due to CLD & $20.0[10.0-30.0]$ & $30.0[10.0-50.0]$ & $60.0[47.5-70.0]$ & $40.0[20.0-70.0]$ & $40.0[20.0-60.0]$ \\
\hline $\begin{array}{l}\% \text { of the people whose daily activities were } \\
\text { affected, mean }(95 \% \mathrm{Cl})\end{array}$ & $80.3(74.4-86.3)$ & $80.5(76.9-84.1)$ & $98.0(96.5-99.6)$ & $90.0(83.7-96.3)$ & $86.4(84.4-88.5)$ \\
\hline
\end{tabular}

Data are in median [interquartile range] unless stated otherwise. $\mathrm{Cl}$ confidence interval; CLD chronic lung disease. Total number of participants (numbers of employed population): Uganda $N=173$ (81), Vietnam 471 (134), Kyrgyzstan 306 (40), Greece 90 (15), and total 1040 (270). Due to different population characteristics per country, data should be interpreted within the country's context and not be used to directly compare between countries 

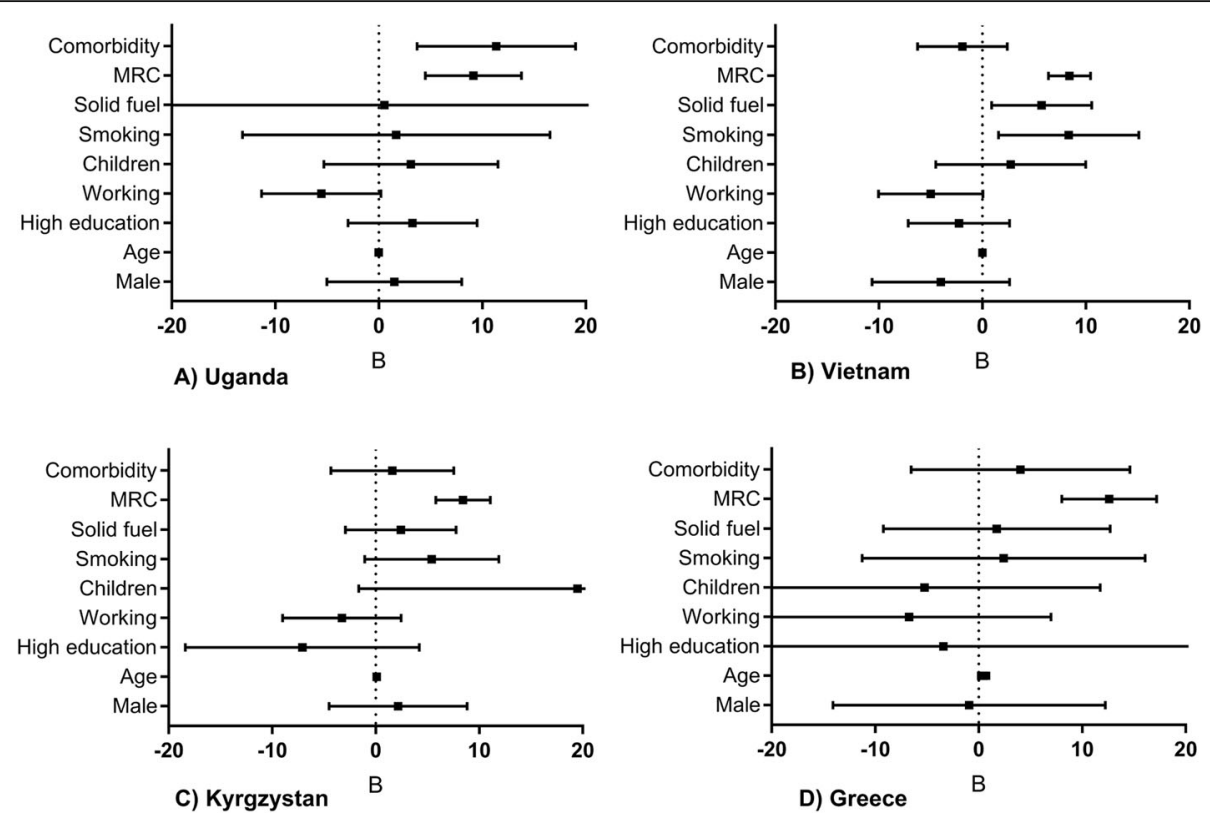

Fig. 3 Multivariable regressions per country. Mean unstandardized B (95\%Cl). MRC = medical research council breathlessness scale (ranging 1-5). Age (years). a Uganda, b Vietnam, c Kyrgyzstan, d Greece

Comparison of CLD-related impairment to impairment due to other chronic diseases in low-resource settings is difficult due to a paucity of data. A large systematic review reported on more than 80 studies assessing WPAI due to chronic disease, yet the settings described were almost exclusively in high-income countries. The handful of studies that also included lowincome countries did not report their results separately for the low-income countries [23].

To our knowledge, this is the first large $(N>1000)$ study to focus on the socioeconomic burden of CLDs in low-resource settings across the world providing data from validated and well-accepted instruments (WPAI, MRC-scale). This paper furthermore answers the call for robust studies identifying modifiable predictors for CLD-related impairment [25]. While some predictors

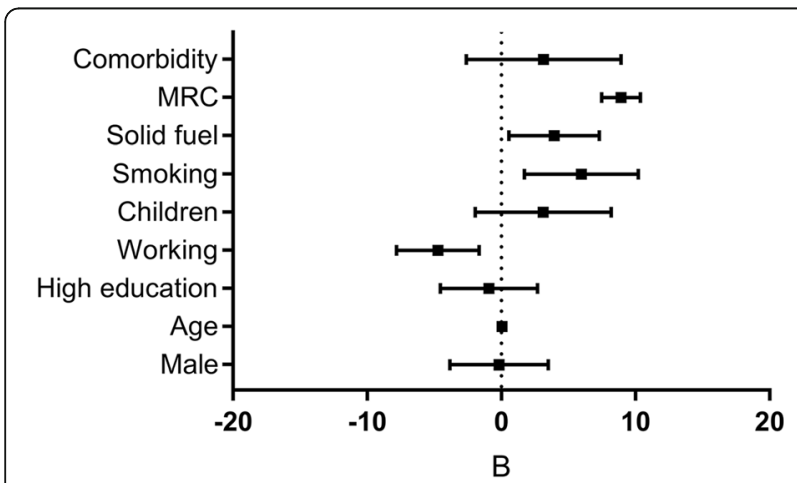

Fig. 4 Total multivariable regression. Mean unstandardized B (95\%Cl). MRC = medical research council breathlessness scale (1-5). Age (years) were previously reported for high-resource settings [35$37,40]$, we have identified a predictor specifically relevant to low-resource settings: solid fuel use. Another strength of our study is the use of identical, yet contextually tailored, methods across four diverse settings, (Additional file 1: Appendix 2 Table E1) improving the fit with the local situation. Some limitations should also be noted. The inclusion of only spirometry-confirmed CLD-patients might lead to selection bias; in lowresource settings patients possibly seek costly healthcare when more severely-ill, and when more severely-ill, impairment scores are higher [17, 43]. Yet given frequent CLD-misdiagnosis in the absence of spirometry [44], particularly in low-resource settings, we valued this criterion. On the one hand, misclassification due to variable spirometry interpretation or other causes for airflow obstruction (post-tuberculosis, childhood respiratory infections) cannot be fully ruled out. On the other hand, other causes would result in the need for similar interventions: reduction of occupational and household air pollution, smoking cessation, pulmonary rehabilitation, etc. Also, we had no control group in our study while socioeconomic data in low-resource settings are scarce; this made it difficult to compare our results to a healthy population. Besides, the actual population-based socioeconomic impact may be underestimated in our study. People frequently missing work might be forced to leave, particularly in more physically demanding jobs as is common in low-resource settings. Unfortunately, we cannot derive the number of early-retirements due to CLD from our data. Lastly, following the WPAI- 

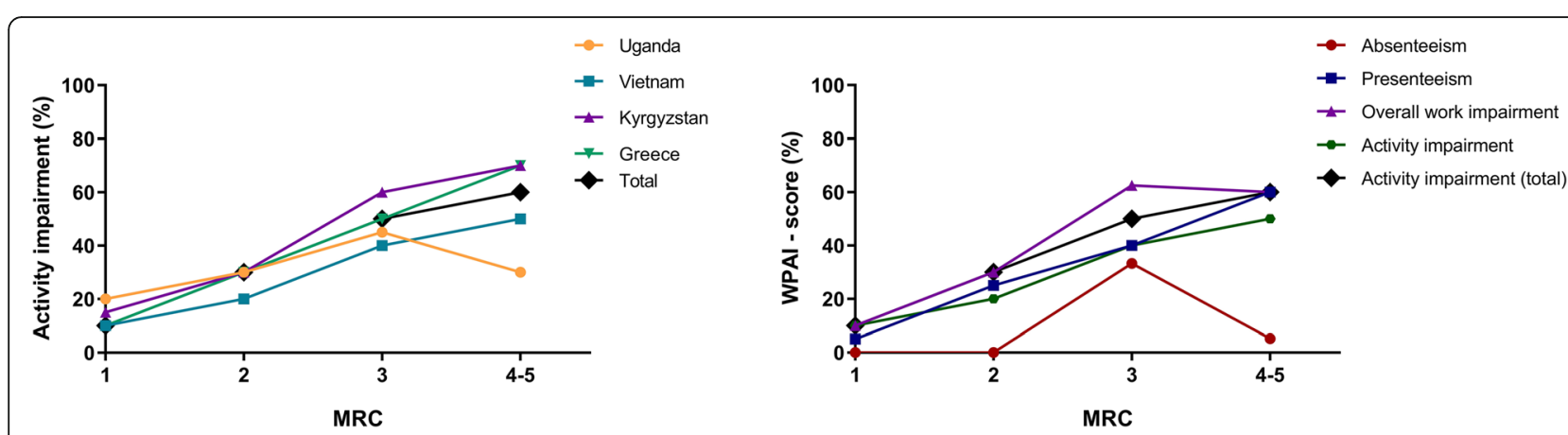

Fig. 5 WPAI and MRC-score. MRC = medical research council breathlessness scale (ranging 1-5). WPAI = work productivity and activity impairment in median \%. Left: Activity impairment per MRC-score per country; Uganda $N=172$ (1 missing MRC value), Vietnam N=471, Kyrgyzstan N=306, Greece $N=90$, and total $N=10$. Due to different population characteristics per country, data should be interpreted within the country's context and not be used to directly compare between countries. Right: WPAI per MRC-score; Absenteeism N=260, presenteeism $N=268$, overall work impairment $N=259$, activity impairment (270), total activity impairment $N=1039$

questionnaire in its validated form, we only assessed absenteeism and presenteeism for those working for an income. We recommend future studies to apply all relevant questions not only to those "currently employed (working for pay)", but also to those self-employed or working for subsistence, as is common in LMICs.

Nevertheless, the substantial WPAI-scores we have observed imply a high socioeconomic burden due to CLDs in low-resource settings. Considering widescale underdiagnosis of CLD, particularly in low-resource settings, costs may be even higher than policymakers may realize $[45,46]$. The risk factors we identified could provide potential leads for combatting impairment. Policymakers could introduce awareness-programs to educate populations on the risks of tobacco- and solid fuel use, and on affordable solutions (e.g. clean stoves). Furthermore, enhanced self-management and pulmonary rehabilitation programs could benefit the factor breathlessness severity [47]. Self-management could be challenging in lowresource settings due to more scarce availability of medications, limited access to healthcare, or widespread overestimations on disease control [3, 4, 48, 49]. Medications should therefore be available at economic costs [50], health infrastructures need to facilitate continuity of care [4], and healthcare workers should educate patients on disease control. Concurrently, although four diverse low-resource settings were assessed in our study, causality and generalizability of our findings should be evaluated further.

\section{Conclusions}

Our results showed that although relatively limited worktime was missed due to CLD in low-resource settings, the disease related productivity- and activity impairment was substantial. Severity of breathlessness, smoking, and solid fuel use were significant modifiable risk factors for impairment. Our results warrant increased awareness on the impact of CLD and the risk factors, preventive actions regarding tobacco and solid fuel use, and enhanced clinical management of CLD in low-resource settings by healthcare workers, policymakers, patients, and employers alike.

\section{Supplementary information}

Supplementary information accompanies this paper at https://doi.org/10. 1186/s12931-019-1255-z.

Additional file 1: STROBE checklist, Methods in detail, Questionnaire, Outcomes detailed per country.

\section{Abbreviations}

ACO: Asthma-COPD overlap; CLD: Chronic lung disease; COPD: Chronic obstructive pulmonary disease; FRESH AIR: Free Respiratory Evaluation and Smoke-exposure reduction by primary Health cAre Integrated gRoups; IQR: Interquartile range; MRC: Medical research council; WPAI: Work productivity and activity impairment

\section{Acknowledgements}

We thank all field researchers, physicians, and participants involved in this study. We thank Birgit Hasenack (Leiden University Medical Centre (LUMC), Leiden, the Netherlands) for her support by a thorough literature search into available local data, and Nan van Geloven (LUMC) and Judith Vonk

(University Medical Center Groningen) for their statistical advice. Lastly, we acknowledge REDCap (Research Electronic Data Capture) for facilitating a secure, web-based application for capturing research data.

FRESH AIR collaborators: Pham Le An, Marilena Anastasaki, Azamat Akylbekov, Andy Barton, Antonios Bertsias, Pham Duong Uyen Binh, Job FM van Boven, Evelyn A Brakema, Dennis Burges, Lucy Cartwright, Vasiliki E Chatzea, Niels H Chavannes, Liza Cragg, Tran Ngoc Dang, llyas Dautov, Berik Emilov, Irene Ferarrio, Frederik A van Gemert, Ben Hedrick, Le Huynh Thi Cam Hong, Nick Hopkinson, Elvira Isaeva, Rupert Jones, Corina de Jong, Sanne van Kampen, Winceslaus Katagira, Bruce Kirenga, Jesper Kjærgaard, Rianne MJJ van der Kleij, Janwillem Kocks, Le Thi Tuyet Lan, Tran Thanh Duv Linh, Christos Lionis, Kim Xuan Loan, Maamed Mademilov, Andy McEwen, Patrick Musinguzi, Rebecca Nantanda, Grace Ndeezi, Sophia Papadakis, Hilary Pinnock, Jillian Pooler, Charlotte C Poot, Maarten J Postma, Anja Poulsen, Pippa Powell, Nguyen Nhat Quynh, Susanne Reventlow, Dimitra Sifaki-Pistolla, Sally Singh, Talant Sooronbaev, Jaime Correia de Sousa, James Stout, Marianne Stubbe Østergaard, Aizhamal Tabyshova, Ioanna Tsiligianni, Tran Diep Tuan, James Tumwine, Le Thanh Van, Nguyen Nhu Vinh, Simon Walusimbi, Louise Warren, Sian Williams. 


\section{Authors' contributions}

$E B, A T$, and JB designed the study, and tailored the protocol to each national situation together with all authors; AT, MA, TLN and SW coordinated the national data collection; $\mathrm{EB}$ and JB coordinated the overall process; $\mathrm{TS}, \mathrm{CL}$, PLA, and BK were national lead investigators, NC was the principal investigator of the overall FRESH AIR project; EB analyzed the data and wrote the manuscript. AT and JB provided feedback at each version. RK provided advice in multiple research stages and at multiple versions of the manuscript. All authors gave input to the manuscript and approved the last version. On behalf of the FRESH AIR collaborators.

\section{Funding}

This study was funded by the EU Research and Innovation program Horizon2020 (Health, Medical research and the challenge of ageing) under grant agreement no. 680997. The funders had no role in study design, data collection, data analysis, data interpretation, or writing of the report. All authors had full access to all the data and EB, and JB had the final responsibility for the decision to submit the study for publication.

\section{Availability of data and materials}

Individual de-identified participant data and meta-data can be shared upon reasonable request. This includes the study protocol, data-dictionaries with details on data cleaning and meeting minutes describing considerations for data analysis. Within reasonable time after email request data will be shared via a secure webbased system.

\section{Ethics approval and consent to participate}

Participants provided written, informed consent. In the three Kyrgyz hospitals where we administered the questionnaire per telephone, verbal consent was provided instead. The study was approved by each local research ethical review board: the 7th Health Region of Crete (protocol 6951;05/27/2016), National Center of Cardiology and Internal Medicine in Bishkek (5;03/03/ 2016), Mulago Research and Ethics Committee (971;05/24/2016), and Ho Chi Minh City University of Medicine and Pharmacy (188/DHYD-HD;06/27/2016).

\section{Consent for publication}

Not applicable.

\section{Competing interests}

None to declare. Part of the results of this study have been previously reported in preliminary form as an abstract [51].

\section{Author details}

'Department of Public Health and Primary Care, Leiden University Medical Center, Postzone V0-P, Postbus 9600, 2300 RC Leiden, The Netherlands. ${ }^{2}$ Pulmonary Department, National Center of Cardiology and Internal Medicine, Bishkek, Kyrgyzstan. ${ }^{3}$ Unit of Global Health, Department of Health Sciences, University of Groningen, University Medical Center Groningen, Groningen, The Netherlands. ${ }^{4}$ Clinic of Social and Family Medicine, School of Medicine, University of Crete, Heraklion, Crete, Greece. ${ }^{5}$ University of Medicine and Pharmacy, Ho Chi Minh City, Vietnam. ${ }^{6}$ Department of Medicine and Makerere Lung Institute, Makerere University, Kampala, Uganda. ${ }^{7}$ Department of General Practice \& Elderly Care Medicine, University of Groningen, University Medical Center Groningen, Groningen Research Institute for Asthma and COPD (GRIAC), Groningen, The Netherlands.

\section{Received: 6 August 2019 Accepted: 5 December 2019}

\section{Published online: 21 December 2019}

\section{References}

1. World Health Organization. Chronic respiratory diseases. 2018. http://www. who.int/respiratory/en/. Accessed 8 Oct 2019.

2. World Health Organization. Global Surveillance, prevention and control of chronic respiratory diseases: a comprehensive approach. 2007. http://www. who.int/gard/publications/GARD\%20Book\%202007.pdf. Accessed 7 Oct 2019.

3. Pleasants RA, Riley IL, Mannino DM. Defining and targeting health disparities in chronic obstructive pulmonary disease. Int J Chron Obstruct Pulmon Dis. 2016;11:2475-96.

4. Beran D, Zar HJ, Perrin C, Menezes AM, Burney P, Forum of international respiratory societies working group $\mathrm{c}$. Burden of asthma and chronic obstructive pulmonary disease and access to essential medicines in lowincome and middle-income countries. Lancet Respir Med. 2015;3:159-70.

5. Martinez FD. Early-life origins of chronic obstructive pulmonary disease. $\mathrm{N}$ Engl J Med. 2016:375:871-8.

6. Lee AG, Kaali S, Quinn A, Delimini R, Burkart K, Opoku-Mensah J, Wylie BJ, Yawson AK, Kinney PL, Ae-Ngibise KA, et al. Prenatal household air pollution is associated with impaired infant lung function with sex-specific effects: evidence from GRAPHS, a cluster randomized Cookstove intervention trial. Am J Respir Crit Care Med. 2019;199(6):738-746.

7. Townend J, Minelli C, Mortimer K, Obaseki DO, Al Ghobain M, Cherkaski H, Denguezli M, Gunesekera K, Hafizi H, Koul PA, et al. The association between chronic airflow obstruction and poverty in 12 sites of the multinational BOLD study. Eur Respir J. 2017;49:1601880. https://doi.org/10. 1183/13993003.01880-2016.

8. Brakema EA, Tabyshova A, Kasteleyn MJ, Molendijk E, van der Kleij R, van Boven JFM, Emilov B, Akmatalieva M, Mademilov M, Numans ME, et al. High COPD prevalence at high altitude: does household air pollution play a role? Eur Respir J. 2019;53:1801193. https://doi.org/10.1183/13993003.01193-2018.

9. Soriano JB, Polverino F, Cosio BG. What is early COPD and why is it important? Eur Respir J. 2018;52:1801448. https://doi.org/10.1183/13993003.01448-2018.

10. Kurmi OP, Semple S, Simkhada P, Smith WC, Ayres JG. COPD and chronic bronchitis risk of indoor air pollution from solid fuel: a systematic review and meta-analysis. Thorax. 2010;65:221-8.

11. Siddharthan T, Grigsby MR, Goodman D, Chowdhury M, Rubinstein A, Irazola V, Gutierrez L, Miranda JJ, Bernabe-Ortiz A, Alam D, et al. Association between household air pollution exposure and chronic obstructive pulmonary disease outcomes in 13 low- and middle-income country settings. Am J Respir Crit Care Med. 2018;197:611-20.

12. Glass RI, Rosenthal JP. International Approach to Environmental and Lung Health. A perspective from the Fogarty International Center. Ann Am Thorac Soc. 2018;15:S109-13.

13. Lopez-Campos JL, Tan W, Soriano JB. Global burden of COPD. Respirology. 2016;21:14-23.

14. Brakema EA, van Gemert FA, van der Kleij R, Salvi S, Puhan M, Chavannes $\mathrm{NH}$, collaborators FA. COPD's early origins in low-and-middle income countries: what are the implications of a false start? NPJ Prim Care Respir Med. 2019;29:6.

15. Miller RL, Lawrence J. Understanding Root Causes of Asthma. Perinata environmental exposures and epigenetic regulation. Ann Am Thorac Soc. 2018;15:S103-8.

16. Magitta NF, Walker RW, Apte KK, Shimwela MD, Mwaiselage JD, Sanga AA, Namdeo AK, Madas SJ, Salvi SS. Prevalence, risk factors and clinical correlates of COPD in a rural setting in Tanzania. Eur Respir J. 2018;51: 1700182. https://doi.org/10.1183/13993003.00182-2017.

17. Miravitlles M, Ribera A. Understanding the impact of symptoms on the burden of COPD. Respir Res. 2017;18:67.

18. McKee M, Balabanova D, Basu S, Ricciardi W, Stuckler D. Universal health coverage: a quest for all countries but under threat in some. Value Health. 2013;16:S39-45.

19. FitzGerald JM, Al Efraij K. Asthma in low-income and middle-income countries: an urgent call to action. Thorax. 2018;73(10):898-899.

20. Sadatsafavi M, Rousseau R, Chen W, Zhang W, Lynd L, FitzGerald JM. The preventable burden of productivity loss due to suboptimal asthma control: a population-based study. Chest. 2014;145:787-93.

21. van Boven JF, Vegter $S$, van der Molen T, Postma MJ. COPD in the working age population: the economic impact on both patients and government. COPD. 2013;10:629-39.

22. Fletcher MJ, Upton J, Taylor-Fishwick J, Buist SA, Jenkins C, Hutton J, Barnes N, Van Der Molen T, Walsh JW, Jones P, Walker S. COPD uncovered: an international survey on the impact of chronic obstructive pulmonary disease [COPD] on a working age population. BMC Public Health. 2011;11:612.

23. Miller PS, Hill H, Andersson FL. Nocturia work productivity and activity impairment compared with other common chronic diseases. Pharmacoeconomics. 2016;34:1277-97.

24. Gronseth R, Erdal M, Tan WC, Obaseki DO, Amaral AFS, Gislason T, Juvekar SK, Koul PA, Studnicka M, Salvi S, et al. Unemployment in chronic airflow obstruction around the world: results from the BOLD study. Eur Respir J. 2017:50:1700499. https://doi.org/10.1183/ 13993003.00499-2017.

25. Rai KK, Adab P, Ayres JG, Jordan RE. Systematic review: chronic obstructive pulmonary disease and work-related outcomes. Occup Med (Lond). 2018;68:99-108. 
26. Cragg L, Williams S, Chavannes NH. FRESH AIR: an implementation research project funded through horizon 2020 exploring the prevention, diagnosis and treatment of chronic respiratory diseases in low-resource settings. NPJ Prim Care Respir Med. 2016;26:16035.

27. Fabbri LM, Hurd SS, Committee GS. Global Strategy for the Diagnosis, Management and Prevention of COPD: 2003 update. Eur Respir J. 2003(22):1-2.

28. Global Initiative for Asthma: Global Strategy for Asthma Management and Prevention. 2016. www.ginasthma.org. Accessed 8 Jan 2018.

29. Bestall JC, Paul EA, Garrod R, Garnham R, Jones PW, Wedzicha JA. Usefulness of the Medical Research Council (MRC) dyspnoea scale as a measure of disability in patients with chronic obstructive pulmonary disease. Thorax. 1999:54:581-6.

30. Reilly MC, Zbrozek AS, Dukes EM. The validity and reproducibility of a work productivity and activity impairment instrument. Pharmacoeconomics. 1993:4:353-65

31. Akinbami $\sqcup$, Sullivan SD, Campbell JD, Grundmeier RW, Hartert TV, Lee TA, Smith RA. Asthma outcomes: healthcare utilization and costs. J Allergy Clin Immunol. 2012;129:S49-64

32. Prasad M, Wahlqvist $P$, Shikiar $R$, Shih $Y C$. A review of self-report instruments measuring health-related work productivity: a patient-reported outcomes perspective. Pharmacoeconomics. 2004;22:225-44.

33. Reilly Associates. WPAI Translations. 2015. http://www.reillyassociates.net/ WPAl_Translations.html. Accessed 12 Dec 2015.

34. Rennard S, Decramer M, Calverley PM, Pride NB, Soriano JB, Vermeire PA, Vestbo J. Impact of COPD in North America and Europe in 2000: subjects' perspective of confronting COPD international survey. Eur Respir J. 2002;20:799-805.

35. DiBonaventura M, Paulose-Ram R, Su J, McDonald M, Zou KH, Wagner JS, Shah $H$. The impact of COPD on quality of life, productivity loss, and resource use among the elderly United States workforce. COPD. 2012;9:46-57.

36. Gruenberger JB, Vietri J, Keininger DL, Mahler DA. Greater dyspnea is associated with lower health-related quality of life among European patients with COPD. Int J Chron Obstruct Pulmon Dis. 2017;12:937-44.

37. Pavord ID, Mathieson N, Scowcroft A, Pedersini R, Isherwood G, Price D. The impact of poor asthma control among asthma patients treated with inhaled corticosteroids plus long-acting beta2-agonists in the United Kingdom: a cross-sectional analysis. NPJ Prim Care Respir Med. 2017;27:17.

38. Zhao J, Li M, Wang Z, Chen J, Zhao J, Xu Y, Wei X, Wang J, Xie J. Role of PM2.5 in the development and progression of COPD and its mechanisms. Respir Res. 2019;20:120.

39. Roche N, Reddel HK, Agusti A, Bateman ED, Krishnan JA, Martin RJ, Papi A, Postma D, Thomas M, Brusselle $\mathrm{G}$, et al. Integrating real-life studies in the global therapeutic research framework. Lancet Respir Med. 2013;1:e29-30.

40. Rai KK, Adab P, Ayres JG, Siebert WS, Sadhra SS, Sitch AJ, Fitzmaurice DA, Jordan RE, team* Br. Factors associated with work productivity among people with COPD: Birmingham COPD cohort. Occup Environ Med. 2017;74:859-67.

41. Chen H, Blanc PD, Hayden ML, Bleecker ER, Chawla A, Lee JH, Group TS. Assessing productivity loss and activity impairment in severe or difficult-totreat asthma. Value Health. 2008;11:231-9.

42. Hansel NN, Romero KM, Pollard SL, Bose S, Psoter KJ, JU L, Johnson C, Williams D, Curriero FC, Breysse $\mathrm{P}$, et al. Ambient air pollution and variation in multiple domains of asthma morbidity among Peruvian children. Ann Am Thorac Soc. 2019;16:348-55.

43. Johnson KM, Bryan S, Ghanbarian S, Sin DD, Sadatsafavi M. Characterizing undiagnosed chronic obstructive pulmonary disease: a systematic review and meta-analysis. Respir Res. 2018;19:26.

44. Heffler E, Crimi C, Mancuso S, Campisi R, Puggioni F, Brussino L, Crimi N. Misdiagnosis of asthma and COPD and underuse of spirometry in primary care unselected patients. Respir Med. 2018;142:48-52.

45. Diab N, Gershon AS, Sin DD, Tan WC, Bourbeau J, Boulet LP, Aaron SD Underdiagnosis and Overdiagnosis of chronic obstructive pulmonary disease. Am J Respir Crit Care Med. 2018:198:1130-9.

46. Aaron SD, Boulet LP, Reddel HK, Gershon AS. Underdiagnosis and Overdiagnosis of asthma. Am J Respir Crit Care Med. 2018;198:1012-20.

47. McCarthy B, Casey D, Devane D, Murphy K, Murphy E, Lacasse Y. Pulmonary rehabilitation for chronic obstructive pulmonary disease. Cochrane Database Syst Rev. 2015;2:CD003793.

48. Salvi SS, Apte KK, Dhar R, Shetty P, Faruqi RA, Thompson PJ, Guleria R. Asthma insights and Management in India: lessons learnt from the Asia Pacific - asthma insights and management (AP-AIM) study. J Assoc Physicians India. 2015;63:36-43.
49. Ding B, Small M. Disease burden of mild asthma in China. Respirology. 2018, 23:369-77.

50. Nguyen HV, Nadkarni NV, Sankari U, Mital S, Lye WK, Tan NC. Association between asthma control and asthma cost: results from a longitudinal study in a primary care setting. Respirology. 2017;22:454-9.

51. Job FM, van Boven EAB, Walusimbi S, Anastasaki M, Tabyshova A, Nguyen L, Lionis C, Tsiligianni I, Kirenga BJ, An PL, Sooronbaev T, Postma MJ, Chavannes NH. Late Breaking Abstract - Health economic burden of asthma/COPD in Uganda, Vietnam, Kyrgyzstan and Greece: FRESH AIR results. Eur Respir J: OA2911. 2017;2017:50.

\section{Publisher's Note}

Springer Nature remains neutral with regard to jurisdictional claims in published maps and institutional affiliations.
Ready to submit your research? Choose BMC and benefit from:

- fast, convenient online submission

- thorough peer review by experienced researchers in your field

- rapid publication on acceptance

- support for research data, including large and complex data types

- gold Open Access which fosters wider collaboration and increased citations

- maximum visibility for your research: over $100 \mathrm{M}$ website views per year

At BMC, research is always in progress.

Learn more biomedcentral.com/submissions 